to the change of the legal consciousness of the new generation Z due to the constant interaction with information technology and the impact of the Internet, as well as the shift of crime in the virtual environment. The authors conclude that new approaches to the prevention of illegal behavior of minors and the formation of their legal consciousness in the new formation is needed.

Keywords: public safety, post-industrial digital society, social reproduction, juvenile delinquency, legal awareness

АБДУЛЬЗянОВ Артур Рашидович - кандидат социологических наук, ведущий научный сотрудник Центра семьи и демографии Академии наук Республики Татарстан, генеральный директор Федерации автошкол Республики Татарстан (420111, Россия, Республика Татарстан, г. Казань, ул. Лево-Булачная, 35a;gailj_07@bk.ru)

\title{
БЕЗОПАСНОСТЬ ДОРОЖНОГО ДВИЖЕНИЯ В СИСТЕМЕ ГОСУДАРСТВЕННОЙ ПОЛИТИКИ CTPAHЫ
}

Аннотация. В статье рассматривается проблема обеспечения безопасности дорожного движения как приоритетная задача государственной политики страны. Эффективная работа в данной сфере способствует снижению депопуляции населения, а также экономических затрат, связанных с последствиями дорожно-транспортных происшествий, что способствует социально-экономическому развитию страны. Ключевые слова: безопасность, безопасность дорожного движения, государственная политика, Госавтоинспекция

Сегодня одной из острейших социальных проблем в мире является проблема безопасности дорожного движения, поскольку на автомобильных дорогах всех стран наблюдается высокий уровень аварийности, что, в свою очередь, приводит к постоянному росту числа погибших и пострадавших в дорожнотранспортных происшествиях.

Дорожно-транспортные происшествия носят социальный и экономический характер. По сведениям Всемирной организации здравоохранения, каждый год на дорогах всего мира гибнут свыше 1,2 млн чел., в т.ч. больше 163 тыс. детей, не достигших возраста 15 лет. По прогнозам данной организации, проблема дорожно-транспортного травматизма может стать к 2020 г. еще более серьезной и занять 3-е место среди первостепенных причин смерти и телесных повреждений у людей ${ }^{1}$. Суммарная убыль населения от дорожно-транспортных происшествий составляет более 2,1\% [Блинкин 2012: 18]. Во всем мире на сегодняшний день дорожные происшествия на дорогах (аварии) являются основной причиной гибели и инвалидности людей в возрастном диапазоне от 3 до 35 лет. Дорожно-транспортные происшествия в развитых странах обусловливают ежегодные потери в размере от 1 до 3\% внутреннего валового продукта, а в развивающихся - издержки еще больше. Для мировой экономики уже сейчас ущерб от дорожно-транспортного происшествия носит и экономический характер: для экономики всего мира он насчитывает примерно 600 млрд евро в год. В свою очередь, в экономически развитых странах ситуация с безопасностью дорожного движения за последние 30 лет стабилизировалась и даже улучшилась, но

\footnotetext{
1 Доклад о состоянии безопасности дорожного движения в мире: краткий обзор ВОЗ. Доступ: http:// apps.who.int/iris/bitstream/handle/10665/70041/WHO_NMH_VIP_09.01_rus.pdf;jsessionid=D71451A22B 351F65A284BC5DAF7BE68E?sequence=5 (проверено 18.08.2018).
} 
в развивающихся странах положение регрессирует в связи с двумя причинами - резким ростом автомобильного парка и недостаточным финансированием работы по профилактике аварийности на дорогах. В качестве причин также выступают: острое несоответствие дорожно-транспортной инфраструктуры потребностям общества и государства в безопасном дорожном движении; недостаточная эффективность деятельности системы гарантий безопасности дорожного движения; низкая дисциплина всех участников дорожно-транспортного движения. Проблема гарантии безопасности дорожного движения превращается в глобальный вызов для всего общества. Данный факт может оказать сильное негативное влияние на национальную безопасность стран, в т.ч. и Российской Федерации.

Следовательно, за последние 10 лет проблема аварийности на дорогах России приобрела особую остроту. Причиной является несоответствие дорожно-транспортной инфраструктуры потребностям общества и государства в гарантии безопасности дорожного движения. Наблюдается усугубление ситуации с дорожно-транспортным травматизмом. Несмотря на то что число аварий повысилось незначительно, однако число погибших выросло на 5,2\% (1 386 чел.).

Диапазон распространения и характер проблемы, связанной с безопасностью дорожного движения в РФ, а также последствия аварий (экономические, социальные и демографические) оказывают значительное влияние на национальную безопасность нашей страны. Задача осуществления гарантии и обеспечения безопасности дорожного движения может рассматриваться как самостоятельная государственная проблема. Дорожно-транспортные происшествия выступают в качестве серьезнейшей социально-экономической проблемы и в Республике Татарстан ${ }^{1}$. За 2017 г. на территории республики зарегистрированы 4654 дорожно-транспортных происшествия, в которых погибли 425 человек и 5688 получили ранения.

В целях реализации государственной политики в области транспортной системы в Республике Татарстан кабинет министров Республики Татарстан утвердил государственную программу «Развитие транспортной системы в Республике Татарстан на 2014-2022 годы» ${ }^{2}$. Программа заключается в обеспечении дальнейшего развития транспортного комплекса и создании ультрасовременной коммуникационной дорожно-транспортной инфраструктуры, которая будет направлена на удовлетворение потребностей экономики и опережающее развитие инфраструктуры в Республике Татарстан. Важные задачи программы заключаются в создании функционирующей и доступной для всех людей единой системы общественного транспорта на основе формирования рынка услуг, регулируемого в интересах общества и хозяйствующих субъектов, повышения безопасности транспортной системы и совершенствования государственной политики транспортного комплекса Республики Татарстан. Организация и проведение в Республике Татарстан XXVII Всемирной летней Универсиады 2013 и Чемпионата мира по футболу 2018 позволили изменить дорожно-транспортную инфраструктуры столицы республики - Казани. В свою очередь, это привело к урбанизации города и повышению культуры поведения населения на дорогах (пешеходов, водителей, велосипедистов).

Нужно реализовывать различные мероприятия с целью сокращения коли-

1 Республиканская целевая программа «Повышение безопасности дорожного движения в Республике Татарстан». Доступ: http://mindortrans.tatarstan.ru/rus/file/pub/pub_184066.pdf (проверено 15.08.2018).

2 Официальный сайт Министерства транспорта и дорожного хозяйства Республики Татарстан. Доступ: http://mindortrans.tatarstan.ru/gosudarstvennaya-programma-razvitie-transportnoy.htm (проверено 15.08.2018). 
чественного показателя дорожно-транспортных происшествий с летальным исходом. Эта проблема находится в фокусе деятельности по обеспечению безопасности дорожного движения. Генеральная Ассамблея ООН в марте 2010 г. объявила период с 2011 по 2020 г. декадой безопасности движения, чтобы остановить рост числа дорожно-транспортных происшествий и прийти к тенденции их уменьшения. По данным Всемирной организации здравоохранения, предполагается, что за данный период в мире должны быть спасены 5 млн чел.

22 октября 2008 г. правительство РФ утвердило Транспортную стратегию РФ до 2030 года, суть которой заключается в повышении качества транспортного обслуживания предприятий и населения за счет внедрения логистических схем и оптимизации взаимодействия различных видов транспорта, а также повышения безопасности дорожного движения.

Россия вошла в число стран-лидеров по темпам уменьшения смертельных исходов в результате дорожно-транспортных происшествий, значительно опередив многие европейские страны, такие, например, как Австрия, а также Соединенные Штаты Америки. Этому способствовала эффективная реализация программно-целевых подходов к решению проблем, связанных с обеспечением безопасности дорожного движения [Тимакова 2012].

Несмотря на большие достижения, в развитых странах абсолютные значения главных показателей аварийности остаются низкими по сравнению с нашей страной, что свидетельствует о необходимости продолжить работу в направлении обеспечения безопасности дорожного движения. Обеспечение безопасности дорожного движения представляет собой важную форму реализации единой государственной политики в области защиты жизни, имущества и здоровья людей посредством предупреждения дорожно-транспортных происшествий и снижения тяжести их последствий. Исходя из этого, гарантия безопасного дорожного движения является важной областью государственной политики стран всего мира.

Ученый В.Д. Кондратьев разрабатывает научно обоснованную методологию по вопросам повышения безопасности дорожного движения, которая направлена на предотвращение дорожно-транспортных происшествий и уменьшение тяжести их последствий. Ее новизна заключается в создании алгоритма, включающего набор мероприятий, которые влияют на уровень безопасности дорожного движения. Алгоритм состоит из трех основных направлений деятельности: «автомобиль» (ориентация на конструктивные и эксплуатационные составляющие транспортного средства с позиции его состояния для обеспечения безопасности), «дорога» (включает дорожные условия, а именно оборудование улиц и дорог техническими средствами организации дорожного движения с целью обеспечения безопасности участников дорожного движения в целом) и «водитель» (человеческий фактор).

В качестве решения имеющихся проблем исследователь предлагает методику оценки деятельности управлений Государственной инспекции безопасности дорожного движения Министерства внутренних дел, Главного управления внутренних дел, Управления внутренних дел субъекта РФ, выступающую инструментом активизации деятельности сотрудников Госавтоинспекции. Ее применение повысит эффективность функционирования системы Госавтоинспекции в целом [Кондратьев 2008: 43].

Итак, проблема обеспечения безопасности дорожного движения в рамках государственной политики не потеряла своей огромной актуальности, а существенная роль в ее решении принадлежит Государственной инспекции безопасности дорожного движения и, прежде всего, сотрудникам дорожно-патрульной службы Госавтоинспекции. 
Был проведен мониторинг мнений работников Госавтоинспекции Татарстана. В исследовании приняли участие сотрудники данного подразделения, поскольку именно их профессиональная деятельность связана с обеспечением безопасности дорожного движения.

Причины дорожно-транспортных происшествий весьма разнообразны. Но самыми частыми являются игнорирование правил дорожного движения, неисправность автомобиля, превышение скорости движения, слабая подготовка водителей, их замедленная реакция, стресс. Особо опасным считается управление автомобилем водителем в нетрезвом состоянии. Другой причиной дорожно-транспортных происшествий выступает неудовлетворительное состояние дорог. Можно отметить еще много других причин: плохую освещенность дорог, открытые люки, низкую культуру вождения, спешку, утомляемость и т.Д. Данные причины также могут привести к огромным потерям.

Чтобы справиться с ситуацией роста аварийности на дорогах и повысить степень безопасности дорожного движения в России, следует существенно усилить ответственность всех участников движения (водителей, пешеходов, велосипедистов), а также обеспечить справедливость наказания виновных. Исследование показало, что большинство респондентов убеждены, что рост числа дорожнотранспортных происшествий на дорогах происходит именно вследствие нарушения правил дорожного движения со стороны водителей $(81,8 \%)$; о несоблюдении правил безопасности пешеходами заявили 68,2\% опрошенных; за рост числа дорожно-транспортных происшествий винят плохое состояние дорог $25,0 \%$ работников Госавтоинспекции. Для получения более детального ответа было проведено полуструктурированное интервью, в ходе которого были выявлены следующие причины аварийности на дорогах: «невнимательность участников движения, как водителей, так и пешеходов», «плохое освещение дорог», «несоблюдение правил дорожного движения», «низкий уровень культуры вождения» и т.д.

В рамках государственной политики за последние 5 лет проведена большая работа по обеспечению безопасности дорожного движения. Об этом свидетельствуют и ответы, полученные в ходе исследования. Большое число респондентов убеждены, что изменения произошли в лучшую сторону, небольшой процент считают, что особых изменений не произошло, тогда как практически никто из представителей Госавтоинспекции не говорит об изменениях в худшую сторону.

Несмотря на позитивную картину, необходимо продолжить работу по обеспечению безопасности дорожного движения. Большинство сотрудников ГИБДД утверждают, что ситуация на дорогах Республики Татарстан не критическая, но все же необходимо принимать профилактические меры $(72,7 \%)$. Четверть респондентов очень обеспокоены состоянием на дорогах и считают, что ситуация критическая и срочно необходимы меры по предотвращению смертности (25\%). Только $2,3 \%$ опрошенных считают, что на дорогах все хорошо и ситуация не требует принятия срочных и безотлагательных мер.

Для обеспечения безопасности дорожного движения необходимо обучение правилам и культуре поведения на дорогах. В республике модератором воспитания навыков безопасности дорожного движения является президент Рустам Нургалиевич Минниханов - бронзовый призер чемпионата Европы по автокроссу.

Привитие навыков соблюдения правил безопасности начинается с детского возраста. В республике проводится много мероприятий по подготовке детей к безопасному поведению на дорогах. Ежегодно юные автомобилисты Татарстана занимают призовые места не только в российских, но и мировых чемпионатах. Республика много вкладывает в подготовку детей и молодежи. 
Главной в деятельности сотрудников Госавтоинспекции должна стать профилактика аварийности на транспорте, повышенная пропагандистская работа, пробуждение интереса общественности к решению вопросов, связанных с безопасностью дорожного движения, формирование безопасного поведения с самого начала жизненного пути человека, реализация комплексной и целостной программы непрерывного обучения детей и взрослых правилам безопасного поведения на дороге.

На сегодняшний день в Республике Татарстан значительное число дорожнотранспортных происшествий происходят по вине водителей индивидуальных транспортных средств. Это связано с увеличением плотности транспортного потока, низким уровнем профессиональной подготовки водителей и транспортной культуры всех участников дорожного движения. Следовательно, требуется разработать комплекс мер по усилению профилактической работы Госавтоинспекции, направленной на обеспечение безопасности дорожного движения.

Для решения этих проблем необходимы кардинальные изменения мировоззренческих ориентиров на уровне всего общества. Для этого потребуется много времени, т.к. в любой реформе изменение ценностных и моральных установок является наиболее сложным.

Из изложенного выше следует, что проблема безопасности дорожного движения должна решаться на уровне отдельного национального проекта. Решение обширного комплекса задач в сфере безопасности дорожного движения должно стать одним из главных государственных приоритетов обеспечения демографической безопасности в Российской Федерации.

В связи с ростом количественных показателей дорожно-транспортных происшествий, с целью реализации единой государственной политики в сфере безопасности дорожного движения, уменьшения степени дорожно-транспортного травматизма и аварийности следует пропагандировать знания в вопросах, касающихся дорожного движения; улучшать систему обучения детей правильному поведению на дорогах; осуществлять систематический контроль за состоянием дорог, организовывать незамедлительные ремонтно-восстановительные работы на аварийных участках; мобилизовать общественные объединения и организации на работу по предотвращению дорожно-транспортных происшествий.

Итак, социальная значимость проблемы безопасности дорожного движения в системе государственной политики главным образом связана с необходимостью сохранения жизни и здоровья населения РФ. Данная задача, решение которой возможно осуществить за счет улучшения дисциплины и культуры вождения, качества дорожно-транспортной инфраструктуры, что, в свою очередь, приведет к снижению тяжести последствий дорожно-транспортных происшествий (демографического и социально-экономического ущерба), является приоритетной в государственной политике страны.

\section{Список литературы}

Блинкин М.Я. 2012. Безопасность дорожного движения: история вопроса, международный опыт, базовые институции. М.: НИУ ВШЭ. 240 с.

Кондратьев В.Д. 2008. Модели и методы управления безопасностью дорожного движения: дис. ... д.тех.н. Воронеж. 226 с.

Тимакова В.В. 2012. Некоторые аспекты международного опыта в обеспечении безопасности дорожного движения. - Вестник НЦ БЖД. № 2. С. 40-45. 
ABDUL'ZYANOV Artur Rashidovich, Cand.Sci. (Soc.), Leading Researcher of the Center for Family and Demography, Academy of Sciences of the Republic of Tatarstan; General Director of the Federation of Driving Schools of the Republic of Tatarstan(35a Levo-Bulachnaya St, Kazan, Republic of Tatarstan, Russia, 420111; gailj_07@bk.ru)

\section{ROAD SAFETY IN THE SYSTEM OF THE STATE POLICY OF THE COUNTRY}

Abstract. The article considers the problem of ensuring road safety as a priority task of the state policy of the country. In Russia, the problem of accidents has become particularly acute in the last decade due to the mismatch of the road and transport infrastructure with the needs of society and state in ensuring road safety.

Effective work in this area helps to reduce the depopulation, as well as the economic costs associated with the consequences of road accidents, which contributes to the socio-economic development of the country. Therefore, the problem of ensuring road safety within the framework of state policy has not lost its immense urgency and the State Road Safety Inspectorate $(G I B D D)$ and, above all, the traffic police officers (DPS) of the GIBDD play a significant role in its solution.

The problem of road safety should be solved at the level of an independent national project. Solving a huge complex of tasks in the field of road safety should become one of the main state priorities for ensuring Russia's demographic security.

Keywords: safety, traffic safety, state policy, state traffic police

ШУЛЕПИН Михаил Владимирович - аспирант Института социологии Федерального научно-исследовательского социологического центра РАН (117218, Россия, г. Москва, ул. Кржижановского, 24/35, корn. 5; ira7507@rambler.ru)

\section{О ПОВЫШЕНИИ ЭФФЕКТИВНОСТИ ПРОФЕССИОНАЛЬНОЙ ДЕЯТЕЛЬНОСТИ СОТРУДНИКОВ ОРГАНОВ ВНУТРЕННИХ ДЕЛ РФ ПУТЕМ ДОПОЛНИТЕЛЬНОГО ОБРАЗОВАНИЯ}

Аннотация. В настоящее время происходит постоянное реформирование системы МВД в сфере оптимизации численности личного состава. При проведении данного процесса неизбежно возрастает нагрузка на каждого сотрудника органов внутренних дел (ОВД), спектр выполняемых им должностных обязанностей становится более широким. В этой связи имеется острая потребность в создании технологических и методических основ, способствующих процессу повышения эффективности профессиональной деятельности сотрудников ОВД РФ путем дополнительного образования, которые рассмотрены и обоснованы в статье.

Ключевые слова: повышение эффективности, дополнительное образование, профессионализм, технологические основы, методические основы, сотрудники органов внутренних дел РФ

$\mathrm{O}$ собенностью процесса труда сотрудников органов внутренних дел (ОВД) является его строгая регламентация требованиями законов, уставов, инструкций, приказов, правил и других организационно-распорядительных документов. Программы обучения для различных должностных категорий сотрудников ОВД определяют одну общую задачу - осуществление подготовки квалифицированных кадров для ОВД РФ в соответствии с требованиями правоохранительной деятельности [Коблов 2016]. Спецификой профессиональной деятельности сотрудников ОВД является сопутствующее нервно-психическое напряжение, которое требует от сотрудников ОВД не только профессиональ- 